\title{
APROXIMACIÓN AL DISCURSO JUVENTUD COMO CONSTRUCCIÓN SOCIOHISTÓRICO-CULTURAL
}

\author{
ANALISA CASTILLO* \\ MIRIAM LUCERO** \\ MARÍA GASQUEZ ${ }^{* * *}$
}

\begin{abstract}
RESUMEN
En este trabajo se realiza un recorrido histórico en torno a la noción juventud, entendida como un discurso que pone énfasis en las condiciones sociohistóricoculturales que hicieron posible su irrupción. Se inicia el camino en las sociedades primitivas, pasando por la sociedad antigua, medieval, industrial, arribando a la denominada sociedad postindustrial, que denominamos como el momento actual. Este recorrido posibilitó advertir las subjetividades juveniles que acontecieron en distintos momentos históricos, y que han sido valoradas y reconocidas socialmente a través de luchas de reconocimiento social que, muchas veces, dejaron inadvertidas otras formas de habitar la juventud. Finalmente, se sostiene que la construcción de este escrito fue posible a partir de la existencia de diversa bibliografía en torno a la juventud, que la ubica, en la actualidad, como un dominio de saber, que permite ampliar la visión de transitar una etapa de la vida colocando el énfasis en la influencia del contexto social, histórico, cultural, económico y político en la producción de las subjetividades juveniles. En este sentido, el artículo plantea interrogantes a quienes nos encontramos en el campo de la investigación, que posibiliten cuestionarnos qué formas de subjetivación juvenil contribuimos a construir, en el instante en que decidimos 'indagarlas', sin olvidar que los que 'investigamos' al decir, al hablar expresan subjetividad.
\end{abstract}

PALABRAS CLAVE: DISCURSO, SUBJETIVIDADES JUVENILES, CONDICIONES SOCIOHISTÓRICO-CULTURALES

* Licenciada en Psicopedagogía, Docente y Becaria Graduada de Perfeccionamiento de Investigación de la Universidad Nacional del Comahue, Viedma, Argentina. Correo electrónico: analisacastillo@gmail.com.

** Profesora de nivel primario. Diplomada en psicopedagogía y estudiante de cuarto año de la Licenciatura en Psicopedagogía. Universidad Nacional del Comahue, Viedma, Argentina.

Correo electrónico: luceroleiva@yahoo.com.ar.

*** Tesista de la carrera Licenciatura en Psicopedagogía. Universidad Nacional del Comahue, Viedma, Argentina.

Correo electrónico: surgasquez@gmail.com. 


\title{
APROXIMAÇÃO AO DISCURSO DE JUVENTUDE COMO CONSTRUÇÃO SOCIAL, HISTÓRICA E CULTURAL
}

\section{RESUMO}

Neste trabalho, realiza-se um resgate histórico da noção de juventude, entendida como um discurso que enfatiza as condições sociais, históricas e culturais que tornaram possível seu surgimento. Inicia-se pelas sociedades primitivas, passando-se pela sociedade antiga, medieval, industrial, ascendendo à denominada sociedade pósindustrial, ou seja, o momento atual. Esse processo possibilitou focar a atenção nas subjetividades juvenis que marcaram diferentes momentos históricos, que têm sido valorizadas e reconhecidas socialmente através de lutas de reconhecimento social as quais, muitas vezes, obscureceram outras formas de ser jovem. Finalmente, sustentase que a produção deste artigo foi possível a partir da existência de ampla bibliografia sobre juventude, que a situa na atualidade como um domínio do saber que permite ampliar a visão de etapa de transição, enfatizando a influência do contexto social, histórico, cultural, econômico e político na produção das subjetividades juvenis. Neste sentido, propomos a pesquisadores do tema perguntas que possibilitem questionar quais subjetividades juvenis ajudamos a construir ao entrevistar os/as jovens, sem esquecer que ao dizer, falar, estes/as expressam sua subjetividade.

PALAVRAS CHAVE: DISCURSO, SUBJETIVIDADES JUVENIS, CONDIÇÕES SOCIO-HISTÓRICO-CULTURAIS

\section{APPROACHING THE YOUTH SPEECH AS A SOCIO-HISTORIC CULTURAL CONSTRUCTION}

\begin{abstract}
Through this article, youth is understood as a historical route around the notion that puts emphasis in the socio, historical-cultural conditions that made their irruption possible. The beginning of the way into the primitive societies happened through old, medieval, and industrial when society arrived at the denominated postindustrial era, as we named it at this present moment. This route made it possible to notice youth subjectivities that occurred at different historical moments, and that has been valued and recognized socially, through different arguments of social recognition that, often, left other forms inadvertent to inhabit youth. Finally it is maintained that the construction of this writing was possible from the diverse bibliography existence around youth, at present, as a dominion of understanding that the emphasis in the influence of the social context allows us to extend the vision toward the journey to a stage of life placing, historical, cultural, economic and political in the production of the youthful subjectivities. In this sense, the article proposes to install questions to those who were in the field of investigation, which makes it possible to question itself what youth subjectivities we contributed to constructing when investigating those to whom 'we in investigate' without forgetting that when saying, and when speaking, it expresses subjectivity.
\end{abstract}

KEY WORDS: SPEECH, YOUTH SUBJECTIVITIES, SOCIO-HISTORICAL CULTURE CONDITIONS 


\section{INTRODUCCIÓN}

EL PRESENTE ARTÍCULO SURGE de una investigación en curso denominada «Las subjetividades juveniles en la escuela media nocturna», ${ }^{1}$ en la ciudad de Viedma, Provincia de Río Negro, Argentina. El objetivo general es construir conocimiento acerca de las subjetividades de los jóvenes y los sentidos que le otorgan a la escuela media nocturna. El propósito es analizar en las prácticas discursivas de los jóvenes las significaciones que le asignan a sus trayectorias escolares, a los modos de ser alumno y las condiciones que intervienen en el proceso de construcción subjetiva, como también se indaga en la normativa, los enunciados del discurso institucional y social, considerados productores de subjetividad.

Desde una perspectiva cualitativa se aborda el trabajo de campo y la construcción de los datos. Este enfoque pretende rescatar las singularidades de los jóvenes en sus procesos de escolarización. Las estrategias seleccionadas para realizar el estudio son encuestas descriptivas, entrevistas cualitativas abiertas, análisis de documentos referidos a la categoría juventud/es, entre otras actividades.

En este contexto emerge el presente trabajo en torno a la noción discursiva juventud, con el objetivo de conocer las condiciones históricas, culturales y sociales —en los distintos momentos- que hicieron y hacen posible la existencia o no de la misma.

\section{Algunas CONSIDERACIONES}

Indagar el discurso juventud a través del tiempo no supone la búsqueda de un origen, sino la contextualización de su irrupción (Foucault, 1996). Pensar la juventud como noción discursiva implica sostenerla como un acontecimiento que irrumpe y ejerce violencia mencionando aquello que no había sido nombrado, constituyendo una práctica que, en este caso, enunciará las condiciones sociohistórico-culturales que hacen posible la emergencia del discurso joven.

En esta lógica 'ser joven' no sólo tiene que ver con un dato biológico, sino con un sentido socialmente creado y asignado. Es decir, no se

1 Esta investigación es dirigida por María Inés Barilá, codirigida por Teresa Iuri y se desarrolla en el Centro Universitario Regional Zona Atlántica de la Universidad Nacional del Comahue. PI. V04/060. Período 2009-2011. Viedma, Río Negro, Argentina. 
ha sido joven de la misma manera en todas las épocas e incluso, en algunos momentos históricos no han existido jóvenes (Saintout, 2009).

Las sociedades producen límites sociales para designar determinadas etapas de la vida. Tenti Fanfani (2009) señala al respecto que esas fronteras son siempre 'arbitrarias', 'conjeturales' e imprecisas. En este sentido, entiende la juventud como 'clase de edad', es decir, el límite socialmente instaurado tendría que ver con la edad que detenta determinado sector, pero no todos los que poseen la misma edad comparten la misma clase de edad: «[...] no todos los coetáneos comparten las mismas características y experiencias vitales (formar pareja, trabajar, alcanzar la autonomía económica, estudiar, etc.)» (op. cit.:56).

La emergencia de la experiencia escolar, como tiempo de la vida ubicado entre la infancia y la condición de adulto, contribuyó a la instauración del límite social que instauró a la juventud, como tiempo de preparación y espera (op. cit.).

La posición en la estructura de distribución de bienes materiales y simbólicos de la sociedad está determinando diversas formas de vivir la experiencia joven, por lo tanto, no es un estado por el que necesariamente pasan todos los individuos en una determinada sociedad (op. cit.:55-56).

$\mathrm{Al}$ respecto, Marcelo Urresti (2000) expresa que tanto la juventud como la adolescencia son períodos de la vida y grupos de edad en la medida en que distintos estadios históricos de la sociedad los constituyen como tales. Agrega que detrás de la definición social de esos grupos existe una lucha clasificatoria en la que distintos sectores tratan de darle su contenido, definiéndoles un perfil. En pos de esas clasificaciones, la sociedad disputa el acceso a recursos, a su distribución, a la lucha por su control y monopolización (Urresti, 2000:11).

Foucault (1996), con relación a esta cuestión, afirma que en toda sociedad se producen discursos (religiosos, políticos, económicos, educativos) y que esa producción está controlada, seleccionada y redistribuida por algunos procedimientos -internos y/o externos del discurso- que tienen por función conjurar los poderes y peligros, dominar los acontecimientos aleatorios y esquivar la pesada y temible materialidad discursiva. ${ }^{2}$

2 Extraído del Informe final de la Beca de Iniciación a la Investigación de Graduados, otorgada por la Universidad Nacional del Comahue a la Lic. Analisa Castillo, denominada: 'La significación que le otorgan los jóvenes escolarizados a la escuela media nocturna por la que transitan'. Período 2008-2009. 
Plantea que uno de los sistemas de exclusión que afectaría al discurso sería la voluntad de verdad, que se apoya en una base institucional, para que el saber se ponga en práctica en una determinada sociedad y así poder ser valorado, distribuido, repartido y atribuido. En este punto se advierte el juego del discurso con el saber y de ahí su posibilidad de verdad (op. cit.).

Este juego —-saber/verdad - nos aproxima a lo que Foucault (1996) denomina dominios de saber, constituidos por las disciplinas, que son una forma de limitación del discurso, un procedimiento de exclusión al interior del discurso.

Las disciplinas producirían proposiciones que están en la verdad, es decir, habría una relación entre la producción de discursos científicos, la verdad que éstos detentan y el ejercicio del poder que, a través de ellos, es posible.

Esther Díaz (2008) expresa que las prácticas sociales se convierten en dominios de saber que se instauran en una sociedad. Estos dominios constituyen objetos de conocimientos a partir de los cuales se producen conceptos, técnicas para modificar la realidad y los valores éticos. Esto implica que al instaurase un 'nuevo' dominio de saber con todos los elementos anteriormente señalados se produce un cambio en torno a los valores éticos, en otros términos, cambia nuestro concepto de lo bueno y de lo malo ${ }^{3}$, emergiendo nuevas prácticas y nuevos discursos que conllevan al surgimiento de nuevas subjetividades (Díaz, 2008:2).

En este sentido, es posible pensar a la juventud como una condición de facticidad, un modo de encontrarse en el mundo, que articula la moratoria vital, la historicidad de la generación en la que se es socializado y la experiencia de las duraciones y de la temporalidad. (Urresti, 2000:13)

Resumiendo: «ser joven entonces es una forma de la experiencia histórica atravesada por la clase y el género, pero que no depende

3 Esther Díaz (2008) realiza una distinción entre moral y ética, ya que al estar entrelazadas suele confundírselas y utilizárselas como sinónimos. La moral proviene del latín y significa costumbres, que están relacionadas con lo que una sociedad considera como buenas o malas, o sea, están relacionadas con el bien y el mal. Ética, en cambio, proviene del griego y significa norma, normativa, lo que puede confundirse con la moral, porque las costumbres dependen de normas pero desde el tecnicismo de las teorías, ética quiere decir reflexión sobre la moral. 
exclusivamente de ellos, sino que adquiere modalidades diferenciales en ellos» (op. cit.:13).

\section{EL DISCURSO JUVENTUD EN LOS DIFERENTES ACONTECIMIENTOS HISTÓRICOS}

Foucault piensa a los sujetos como construcciones históricas, sujetos que se constituyen a través de la historia, a través de prácticas y de discursos por ello es importante saber qué quisiéramos llegar a ser antes que quiénes somos (Díaz, 2008).

En un trabajo dedicado al estudio de las culturas juveniles, el antropólogo Carles Feixa (1999) se formula una pregunta ¿es universal la juventud? Esta pregunta opera como gatillador a fin de iniciar un recorrido desde las sociedades primitivas hasta la actualidad. En ese pasaje advierte que a la juventud se la considera como condición universal, una fase del desarrollo humano comprendida entre la pubertad fisiológica (condición natural) y el reconocimiento del estatus adulto (condición cultural) que se encontrará en todas las sociedades y momentos históricos (Feixa, 1999:16).

En las sociedades primitivas, es decir, aquellas sociedades segmentarias, sin Estado, la duración y la existencia de la juventud es un tema problemático. El autor expresa que lo único que comparten la mayoría de estas sociedades es el valor que le otorgan a la pubertad, esto supone que para los muchachos, está definida por la maduración fisiológica, que se traduce en fuerza muscular, comienzan a ser considerados culturalmente como agentes productivos; por su parte, para las mujeres, la llegada a la pubertad implica convertirse en agentes reproductivos. Esta travesía se elabora mediante ritos de iniciación, que celebran el ingreso de los individuos a la sociedad (Feixa, 1999:20).

Levi y Schmitt (1996) señalan que en la Grecia clásica ciertos jóvenes ocupaban el espacio público desde una relación profundamente asimétrica con los adultos y a partir de ser cuerpos masculinos deseados, dispuestos al goce adulto (Saintout, 2009).

«La juventud era el tiempo de los aprendizajes, de la emulación, de los concursos; en ese contexto, la relación del erasta — hombre ya hecho- con el joven constituía una de las dimensiones fundamentales» (Levi y Schmitt, 1996:53). La juventud como un tiempo que culmina cuando finaliza esta relación de educación (op. cit.:19).

Las condiciones que hicieron posible, el lugar de la juventud en este período histórico, denominado Sociedad Antigua, tuvieron que ver 
con la emergencia del poder estatal, con los procesos de jerarquización social, división del trabajo y urbanización. Este contexto posibilitó la aparición de un grupo de edad al que se le asignaron tareas educativas y militares. La generación de un excedente económico permitió que una parte de la fuerza de trabajo se destinara a actividades no productivas y que determinados jóvenes (varones de las élites) dedicaran un período de su vida a la formación cívico-militar. Sumado a esto surgen una serie de imágenes culturales y de valores simbólicos sobre la juventud, que la aíslan del resto del cuerpo social (Feixa, 1999:27).

Lo esencial de esta etapa fue la consolidación de instituciones dedicadas a la educación de los jóvenes. La más conocida es la Efebia, que surgió en Atenas en el siglo V. A.C. (op. cit.). El ingreso a la Efebia marcaba la celebración y el reconocimiento público del fin de la infancia. El término efebo significa etimológicamente 'el que ha llegado a la pubertad'; dicho vocablo además de referirse a un fenómeno fisiológico tenía un sentido jurídico. Se ingresaba a un período obligatorio de noviciado social (la efeMa), en la Efebia —institución militar- se educaba a los jóvenes guerreros entre los dieciséis y veintiún años, a través de una serie de ejercicios institucionalizados que combinaban la preparación para la guerra con la formación moral, incluyendo un período de aislamiento muy duro (op. cit.:27).

Con el tiempo dicha institución perdió su carácter militar enfatizando su aspecto educativo, introduciendo a los jóvenes de las élites en el refinamiento de la vida elegante, para ello se requería de una fase de la vida, libre de compromisos para poder prepararse y de esta manera exponer sus opiniones, conquistar una posición preeminente en la sociedad. Aparece así la noción de paideia (o educación) como una base sólida donde se apoyaba la idea de juventud. La educación se vinculaba a ideas de eros, amistad y reforma y se convirtió en un símbolo de la cultura. Se asociaba la juventud a una función cultural, es decir, una fase de la vida dedicada a la educación y a la cultura (op. cit.:28).

Feixa (1999) expresa que en esa época algunos filósofos destacaron el carácter ambivalente de la noción juventud. Por un lado, existía una crisis de la autoridad del adulto, lo que conllevaba a un culto de lo joven y, por otro, se exaltaban diversas características de los jóvenes como la sensualidad, el orgullo, la esperanza, el idealismo, la generosidad, entre otras. Este carácter ambivalente entre jóvenes y viejos se vinculó al elogio del hombre de mediana edad, que era quien ostentaba el poder en la sociedad (Feixa, 1999:28-29). 
En la Roma Antigua también se observa la transición del modelo púber al del efebo; esta transición se realizaba a partir de una decisión que tomaban los páter familias y los miembros del consilium domesticum quienes acordaban declarar púber al joven, conduciéndolo a la plaza pública donde lo despojaban de la toga praetexta y le imponían la toga virile, que señalaba el ingreso en la comunidad política como ciudadano, obteniendo los mismos derechos y deberes que los adultos. Sin embargo, los padres continuaban teniendo la patria potestad sobre sus hijos y sólo en caso de muerte del progenitor, el primogénito obtenía esta potestad si había llegado a la pubertad (Feixa, 1999:29).

En la sociedad romana del siglo II D.C. se produjeron importantes cambios en lo social como en lo económico expresados en la formación de grandes capitales de origen financiero y comercial; acaparamiento de recursos por parte de una minoría dominante; urbanización masiva; desarrollo completo de la esclavitud como relación fundamental de producción, entre otros, que dieron lugar al surgimiento de la juventud entre los varones de las clases privilegiadas, pero con una pérdida progresiva de sus derechos. La madurez social no se adquiría de forma inmediata con la llegada a la pubertad, sino que era postergada hasta los veinticinco años.

El joven, en ese momento, fue reconocido maduro socialmente para asumir la defensa de la patria, pero no para gestionar el propio patrimonio y la res publica. De esta forma se aumenta el control familiar, escolar, moral y penal sobre los jóvenes, es decir, se cercenó su independencia, bajo leyes que se presentaban como una forma de protección hacia los mismos (Feixa, 1999:30).

Tanto en la Grecia clásica como en este período se observa que la definición de juventud fue sólo prerrogativa de los jóvenes varones de clases privilegiadas, las mujeres y esclavos no formaban parte de esta noción (Saintout, 2009:19).

En la sociedad medieval, lo que se conoce como Antiguo Régimen, no se realizaba un rito de iniciación para pasar de la infancia a la adultez. Philippe Ariès (1973:5-6) sustentó sus conocidas teorías sobre la inexistencia de la juventud. La infancia duraba un breve período de tiempo mientras el niño no se podía sostener económicamente, luego el pequeño se insertaba en el mundo adulto sin pasar por la juventud. A partir de los 7 ó 9 años, los niños y niñas eran alejados de sus hogares para aprender las tareas domésticas y los oficios y habilidades, así como el comportamiento en otros aspectos de la vida, a partir del contacto directo con adultos. Esta etapa de aprendizaje duraba hasta los 
14 ó 18 años, tanto en el campo como en la ciudad y en todas las clases sociales (Ariès, 1973:32).

No existía la noción de segregación por grupos de edad. Era natural que se mezclaran menores con adultos en tabernas y lugares de mala fama; las cosas de la vida (como la sexualidad) se aprendían por observación directa.

El grado de independencia de los adolescentes era mucho mayor, a pesar de estar bajo el control de tutores o maestros, lo que se correspondía a un débil sentimiento de cohesión familiar (Ariès, 1973:31). También en el plano religioso los menores eran considerados adultos capaces de distinguir la fe auténtica y de participar en los ritos y mitos del catarismo perseguido: «A los doce años el hombre tiene ya la inteligencia del bien y del mal para recibir nuestra fe», declaraba un propagador cátaro. Los mismos inquisidores no dudaban en condenar a los muchachos de esa edad, incluso a morir en la hoguera (Le Roy Ladurie, 1980:218, en Feixa, 1999:34).

En síntesis, en la Europa medieval no es fácil identificar una fase de la vida correspondiente con lo que hoy se entiende por juventud. En cambio, en la Sociedad Industrial - modernidad - se acentúa la pregunta por el surgimiento de la 'juventud' como realidad social. Frank Musgrove (1965:33) dice que «el joven fue inventado al mismo tiempo que la máquina de vapor» (op. cit.:35).

Se considera a Rousseau como el inventor del joven. En una de sus obras, Emilio, el filósofo describe la adolescencia como un segundo nacimiento, metamorfosis interior, estadio en el cual se despierta el sentido social, la emotividad, la conciencia, fase natural de la vida en donde resultan inevitables las crisis (Lutte 1992; Fischer, 1975, en Feixa, 1999).

Sin embargo, no existe fecha clave que denote el surgimiento de la juventud como condición social —entre las diferentes clases sociales- y como imagen cultural diferente. Aparece en el escenario público en el siglo XX. Su origen se podría rastrear en el proceso de transición del feudalismo al capitalismo, así como en las diversas transformaciones producidas en el seno de instituciones como la familia, la escuela, el ejército y el trabajo (op. cit.).

La primera institución en cambiar fue la familia, desde el siglo XVII el modelo de «apprentissage» entra en crisis. El traslado de los niños fuera de la casa paterna ya no es tan corriente, la familia se empieza a ocupar de la educación y promoción de sus hijos. Con la industrialización, urbanización y nuclearización, estos cambios afectaron primero a la burguesía y, más tarde, se extendieron a otras clases. 
Otra institución clave es la escuela, que debido el desarrollo del comercio y la burocracia deja de estar reservada a los clérigos para convertirse en un instrumento normal de iniciación social.

La juventud, en este punto, emerge como fundamento del dispositivo pedagógico de la escuela media, se configuró un tipo de alumno definido en la pertenencia, identidad y subjetividad propias de la juventud burguesa (Falconi, 2004).

Al respecto Cristina Corea (2002) expresa que con la aparición de la escuela pública, surge la experiencia de la constitución de la figura del ciudadano. A través de la práctica escolar de la lectoescritura se asienta la experiencia escolar del ciudadano y aparece como la práctica esencial de constitución de esa subjetividad (Corea, 2002:1).

En ese momento histórico, determinados jóvenes fueron moldeados por la institución escolar. El respeto por la autoridad, disposición para la obediencia, deseo de progreso, capacidad para adquirir normas básicas de interacción social, constituían la matriz básica de la educabilidad (Duschatzky y Corea, 2008:86) que la escuela compartía en solidaridad con la familia.

La tercera institución que influye —en este caso sólo relativa al género masculino- es el ejército. Con la Revolución Industrial se instaura el servicio militar obligatorio, los varones son separados de su comunidad de origen y pasan a compartir su vida con coetáneos de orígenes muy diversos. Por otra parte, la leva —en sentido de reclutamiento - va generando una cultura propia: las fiestas de quintos (y sus contrapartidas femeninas, como las apolonias), el lenguaje contramilitar, las costumbres sexuales y el consumo de drogas van a delimitar un mundo propiamente juvenil. Surge la noción de que el servicio militar sirve "para hacerse hombres» y que solo al retorno del mismo pueden los muchachos pensar en fundar una familia (Ariès, 1973; Bozon, 1981, en Feixa, 1999).

La cuarta institución es el mundo laboral. La primera industrialización no marcó diferenciaciones de la fuerza de trabajo, el trabajo infantil aumentó, recién en la segunda Revolución Industrial, se los alejó de la industria. En este momento se requirió de más mano de obra y de mayor preparación técnica para desarrollar tareas complejas. Entonces, el sistema industrial demandó de formación básica para jóvenes burgueses y obreros.

Los muchachos y muchachas fueron expulsados del trabajo asalariado y conducidos a un no «mans land laboral y espacial»: la escuela o bien la calle (Keniston, 1981, en Feixa, 1999). 
A finales del siglo XIX, el terreno estaba preparado. Gillis (1981:131) dice que «desde $1870-1900$ se produce el descubrimiento de la adolescencia, a través de la sentencia definitiva entre padres y educadores: los muchachos han de ser muchachos». Este autor también sostiene que en la primera mitad del siglo XX se promueve la «era de la adolescencia», concepto que se extiende a todos los géneros y clases sociales. La escuela secundaria se universaliza, se expulsa del mercado laboral a los jóvenes y surgen las primeras asociaciones juveniles modernas (Feixa, 1999). Finalmente este período es sacudido por las dos guerras mundiales que supusieron momentáneamente regresión de este proceso de extensión social de la juventud.

Luego de un fuerte período de bloques políticos de jóvenes ideológicamente contrapuestos, durante el período de entreguerras emerge, en la segunda mitad del Siglo XX, la juventud como sujeto social, es decir, como actor protagonista en la escena pública, libre de responsabilidades, políticamente pasivo y dócil (op. cit.:41).

En una sociedad de cultura rural o agraria que se transformaba en industrial y postindustrial, comenzaron a modificarse profundamente las condiciones sociales y las imágenes culturales de los jóvenes (op. cit.:42), así es como la construcción de la juventud estuvo ligada con una necesidad de control, tanto desde la perspectiva progresista como de la conservadora. Desde esta postura, ser joven apareció como una patología a corregir y desde la mirada progresista, generalmente retomada en la política social estatal que trabaja con sectores empobrecidos, no se habla de patología sino de 'rescate' de la condición juvenil (Saintout, 2009:21).

En este sentido, Feixa (1999) señala cinco condiciones que 'posibilitaron' el surgimiento de diversas formas de habitar la juventud, instalando distancias cada vez más profundas con las generaciones pasadas.

En primer lugar, la emergencia del Estado de Bienestar facilitó condiciones para el crecimiento económico y para la protección social de los grupos dependientes. Los jóvenes son los sectores más beneficiados por las políticas del bienestar, poseen mayores oportunidades educativas y de ocio, seguridad social, entre otras cuestiones (op. cit.:43).

En este contexto, por el proceso de obligatoriedad escolar llegan más jóvenes a la escuela y traen consigo todo lo que son como clase y cultura; a la escuela secundaria primero llegan los hijos de los grupos sociales subordinados de las áreas urbanas y después de las áreas rurales. Es decir, los tradicionalmente excluidos, hoy convertidos en 
'herederos y becarios', se agregan el grueso de la población (Tenti Fanfani, 2000).

Los jóvenes deben permanecer por más tiempo en las instituciones educativas, se ampliaron los rangos de edad para la adquisición del conocimiento social que no fue más que una forma de control social como un dispositivo de autorregulación. También la sociedad reivindicó la existencia de niños y jóvenes como sujetos de derechos amparados por el Estado (Reguillo, 2000:4).

La segunda condición que se menciona es la crisis de la autoridad patriarcal, condición que conlleva una rápida ampliación de las esferas de libertad juvenil, una revuelta contra todas las formas de autoritarismo.

Como tercera condición se menciona el desarrollo de las sociedades de consumo que ofrecen un espacio específicamente para los jóvenes: moda, adornos, música, entre otros productos destinados a consumidores adolescentes sin demasiadas distinciones de clase.

La cuarta condición se refiere al surgimiento de los medios masivos de comunicación, que articuló un lenguaje universal que hizo posible que los jóvenes comenzaran a identificarse más con sus coetáneos que con los miembros de su clase o etnia. El proceso de modernización en el plano de usos y costumbres supuso una erosión de la moral puritana, dominante desde los orígenes del capitalismo, siendo sustituida por una moral consumista cuyos portadores fueron los jóvenes. Uno de los resultados fue la llamada 'revolución sexual' posibilitada por la difusión de anticonceptivos. Por primera vez en la historia se separó la genitalidad de la procreación, que es la quinta condición que el autor señala (Feixa, 1999:43).

Estas cinco condiciones que describe el antropólogo pueden ejemplificar, aunque de manera un poco arbitraria, el contexto en el que emergen las nuevas formas de habitar la juventud, nuevas formas de subjetivarse joven.

Ignacio Lewkowicz bautizó a la época en la que vivimos como la 'era de la fluidez', la fluidez define una situación (Corea, 2002), un medio radicalmente distinto de aquel que fundó la escuela como parte del proyecto moderno del Estado-Nación.

Actualmente nos encontramos frente a la lógica del agotamiento del Estado-Nación, la potencia soberana del Estado fue sustituida por la potencia soberana del mercado. Esto significa que se produjo una alteración fundamental en el suelo de la producción de subjetividad, ya no se promueven ciudadanos sino consumidores (Duschatzky y Corea, 2008:21). 
En estas condiciones de posibilidad histórica se producen las subjetividades juveniles, las diversas formas de habitar la juventud, en este sentido es que se concibe o se habla de los jóvenes como construcción social, histórica y cultural.

Estos fueron procesos convergentes a una 'modernización cultural' correlativa a la modernización económica y política vivida por todos los países occidentales en la posguerra. La imagen cultural de los jóvenes, a partir de mediados de los setenta, estuvo marcada por el conformismo social, la desmovilización política y el puritanismo. Las drogodependencias y las nuevas formas de violencia juvenil formarían la punta de un iceberg, en la base del cual se encontraba el crecimiento galopante del paro y la demora en la inserción social.

Apalancados en casa y desencantados, la generación de los ochenta aguardaría la entrada a la vida adulta. Cambios como la prolongación de la dependencia familiar, ampliación de las formas de cohabitación previas al matrimonio, largos y discontinuos procesos de inserción laboral, entre otros, que afectaron profundamente el término de la etapa de la juventud. Esto generó el círculo de la postadolescencia que pasó a ser parte de una nueva etapa de la vida (op. cit.:45).

Los años noventa presenciaron tendencias contradictorias. Una de las características de este nuevo modelo de juventud es la influencia de las nuevas tecnologías de la comunicación como video, telefonía digital, informática, Internet, que definen lo que muchos autores denominan la 'cultura juvenil postmoderna', resultado del impacto de los modernos medios de comunicación en un capitalismo cada más transnacional. Este contexto que puede recluir a los jóvenes en un nuevo individualismo o conectarlos con jóvenes de todo el planeta significa una nueva forma de socialización junto a la familia, la escuela o el trabajo (op. cit.).

El relato a través del cual se historizan los discursos sobre los jóvenes deja entrever diversas formas en las que emergen las subjetividades juveniles a través del tiempo, como una etapa transitoria constituida en algunos momentos a partir de la significación que en determinada cultura se otorga a la pubertad; a la relación que se constituye con la subjetividad adulta; al vínculo que establece con la instrucción obligatoria, pero también a la inexistencia de discurso en determinada sociedad y momento histórico.

Feixa (1999) plantea que la juventud aparece como una 'construcción social' relativa en el tiempo y espacio, y que cada sociedad organiza la transición de la infancia a la vida adulta con formas y contenidos variables. 
Si bien este proceso tiene una base biológica, lo importante es la percepción social de estos cambios y las repercusiones para su comunidad. El autor agrega que para que exista juventud deben prevalecer una serie de condiciones sociales como normas, comportamientos e instituciones que diferencien a los jóvenes de otros grupos de edad; como también deben estar presentes una serie de imágenes culturales como valores, atributos y ritos asociados específicamente a ellos (op. cit).

\section{REFLEXIONES FINALES}

No en todos los sitios, ni en todos los momentos históricos ${ }^{4}$ significa lo mismo que a las muchachas le crezcan los pechos y a los muchachos el bigote (Feixa, 1999:18).

En este recorrido por distintos momentos históricos fue posible acercarnos a las condiciones sociales, culturales que hicieron posible la emergencia de la noción juventud. Podemos inferir que esta noción presenta ciertas particularidades:

Es situacional. Responde sólo a contextos delimitados; no se podría hablar de juventud en forma general sin tener en cuenta la especificidad de espacios y tiempos concretos en los que la noción surge.

Es construida. Sobre lo juvenil se dan procesos de disputa y negociación entre las significaciones elaboradas por el lugar que ocupan frente a sus adultos más cercanos - los padres, por ejemplo, e instituciones sociales externas, como la escuela-, en torno a los jóvenes y las culturas juveniles que ingresan y habitan las mismas. Estas significaciones a veces coinciden, otras veces mantienen una relación conflictiva o de negociación, donde se delimita quiénes pertenecen al grupo juvenil y quiénes quedan excluidos del mismo.

Es variable. Se construye y reconstruye permanentemente en la interacción social.

Se produce en lo cotidiano. Sus ámbitos de referencia son íntimos, cercanos, familiares: los barrios, la escuela, el trabajo, la música, los estilos, a moda, Internet, los medios de comunicación, entre otros.

Es transitoria. Dependiendo de tiempos biológicos y socioculturales que los integran o expulsan de la condición juvenil.

$4 \quad$ Las cursivas son nuestras. 
Se construye en relaciones de poder. Se advierte la existencia de construcciones discursivas dominantes, con valor de verdad, que recluyen otras formas subjetivas de habitar la juventud. Hoy las diversas estigmatizaciones por las que transitan determinadas subjetividades juveniles —aunque compartan la misma generación — los alejan del discurso dominante.

Este recorrido ha sido posible debido a la existencia de trabajos investigativos sobre la juventud o juventudes en plural. Es por ello que en este momento es posible hablar de la juventud como un dominio de saber que posibilita - a nuestro entender — ampliar la visión de transitar una etapa de la vida. A través del tiempo, nuestra sociedad ha sistematizado y definido la noción de joven. Actualmente, el énfasis se coloca en el contexto histórico, social, cultural, económico y político que producen diversas subjetividades juveniles.

En este sentido, quienes transitamos el camino de la investigación instalamos un signo de interrogación en torno a qué formas de subjetivación juvenil contribuimos a construir, en el instante en que decidimos 'indagarlas', sin olvidar que los que 'investigamos' al decir, al hablar, expresan subjetividad.

VIEDMA (ARGENTINA), AGOSTO 2010

RECIBIDO: AGOSTO 2010

ACEPTADO: OCTUBRE 2010

\section{REFERENCIAS BIBLIOGRÁFICAS}

COREA, CRISTINA (2002): «¿Qué hace la escuela con la tele? La escuela, los jóvenes y la experiencia mediática». Conferencia de capacitación docente en la CEAP, octubre. Buenos Aires. En: www.estudiolwz.com.ar.

DusChATZKY, Silvia y CRISTINA CoREA (2008): Chicos en banda. Los caminos de la subjetividad en el declive de las instituciones. Buenos Aires: Paidós.

DíAZ, ESTHER (2008): «La educación y los modos de subjetivación, dispositivos éticos y dispositivos disciplinarios». En: www.estherdiaz.com.ar.

FeiXa, Carles (1999): De jóvenes, bandas y tribus. Antropología de la juventud. Barcelona: Editorial Ariel.

FouCAUlt, Michel (1969): La arqueología del saber. Buenos Aires: Siglo XXI. 
REguillo CRUZ, Rossana (2000): Emergencias de culturas juveniles. Estrategias del desencanto. Buenos Aires: Grupo Editorial Norma.

SAintout, FloRencia (2009): Jóvenes: el futuro llegó hace rato. Percepciones de un tiempo de cambios: familia, escuela, trabajo y política. Buenos Aires: Prometeo.

TENTI FANFANI, EMILIO (2008): «La enseñanza media hoy: masificación con exclusión social y cultural». En: Tiramonti y Montes (compiladoras): $L a$ escuela media en debate. Problemas actuales y perspectivas desde la investigación. Buenos Aires: Manantial y FLACSO.

URResti, MARCELo (2000): Una escuela para los adolescentes. Buenos Aires: UNICEF. 